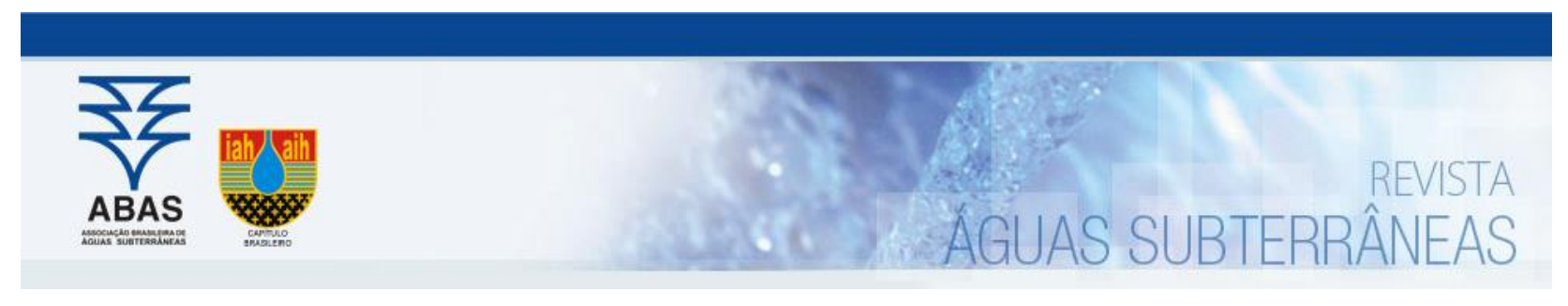

Artigos

\title{
Caracterização estrutural em top-down de aquíferos fraturados: exemplo em Barra Mansa, Rio de Janeiro
}

\section{Top-down structural characterization of fractured aquifers: example in Barra Mansa, Rio de Janeiro}

\author{
Fábio Sartorio1; Reginaldo Antonio Bertolo1; Daphne Silva Pino1; Fernando Augusto Saraiva1 ${ }^{\circledR}$ \\ 1 Centro de Pesquisas de Águas Subterrâneas (CEPAS/USP), São Paulo, SP.

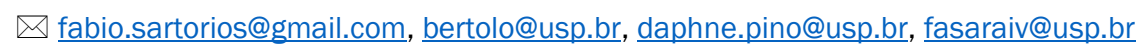

\author{
Palavras-chave: \\ Aquífero Fraturado; \\ Lineamentos; \\ Caracterização Estrutural; \\ Caminhamento Elétrico; \\ Modelo Conceitual.
}

\begin{abstract}
Resumo
No contexto brasileiro, aquíferos cristalinos fraturados têm importância significativa para o abastecimento público e privado nas regiões mais povoadas e de maior relevância econômica, o que justifica a necessidade de se avançar cada vez mais no seu conhecimento. Entretanto, várias das técnicas e ferramentas adequadas para a investigação desse meio geológico ainda são pouco exploradas na totalidade, tanto para as tarefas de locação de novos poços, como para a previsão do comportamento de poluentes em situações de investigação de áreas contaminadas. Neste estudo, pretende-se chamar a atenção para a aplicação conjunta de técnicas convencionais para o desenvolvimento de um modelo conceitual geológico numa área contaminada em aquífero fraturado, cujos resultados embasam as etapas de investigações subsequentes, mais avançadas. A metodologia integra três técnicas tradicionais e não invasivas, com escalas de investigação se desenvolvendo da regional para a local (top-down): (1) análise de lineamentos; (2) amostragem estrutural em afloramentos; e (3) imageamento geofísico pelo método de caminhamento elétrico. No caso estudado, na região de Barra Mansa (RJ), as três técnicas geraram resultados progressivamente consistentes para a melhor caracterização do aquífero, possibilitando a identificação dos trends estruturais e dos principais grupos de fraturas da região. Assim, os lineamentos definidos apresentaram ótima correlação com os trends estruturais observados em campo; similarmente, zonas de baixa resistividade identificadas nos caminhamentos elétricos correspondem com a posição dos lineamentos e das zonas de fraturas. A correlação entre os resultados das três etapas foi fundamental para a melhor compreensão da dinâmica de fluxo do aquífero, estabelecendo, em escala local, o modelo conceitual geológico-estrutural e as estruturas que apresentam maior potencial para fluxo de água e, potencialmente, para o transporte de contaminantes.
\end{abstract}

Abstract

Keywords:

Fractured Aquifer;

Lineaments:

Structural Characterization;

Resistivity Profile;

Conceptual Site Model.

Revisão por pares.

Recebido em: 09/08/2021.

Aprovado em: 25/10/2021.
Fractured crystalline aquifers are of significant importance in Brazil for public and private water supply, especially in the most populated and economically relevant regions, which justifies the need to further advance their study. Nevertheless, the most appropriate techniques and tools for investigating this geological environment are still underemployed, both regarding the location of new wells and the prediction of the pollutant behavior at contaminated sites. This study draws awareness to the joint application of conventional techniques for the development of a geological conceptual model in a contaminated area of a fractured aquifer, which results could support the later advanced stages of investigation. The methodology integrates three traditional and non-invasive techniques, with scales of investigation developing from regional to local (top-down): (1) lineament analysis; (2) structural sampling in outcrops; and (3) geophysical survey imaging, using the 2D resistivity profile method. In the case studied, in the region of Barra Mansa (Rio de Janeiro, Brazil), the three techniques generated progressively consistent results for a better characterization of the aquifer, enabling the identification of structural trends and the main groups of fractures in the region. Thus, the defined lineaments presented an excellent correlation with the structural trends observed in the field; similarly, low resistivity zones identified with the geophysical survey coincided with the location of the lineaments and fracture zones. The correlation between the three steps was essential for a better understanding of the flow dynamics of the aquifer, establishing, at a local scale, the geological-structural conceptual model and the structures that have the greatest potential for water flow and potentially for contaminant transport.

\section{INTRODUÇÃO}

A caracterização estrutural de um aquífero fraturado é essencial para o entendimento de sua dinâmica de fluxo, por vezes constituindo uma atividade desafiadora, devido à intensa anisotropia e heterogeneidade desses meios. Nos casos em que as fraturas são o principal conduto para o transporte da água subterrânea, os principais condicionantes de fluxo são fatores geométricos como abertura, densidade, conectividade, natureza das intersecções de fraturas e distribuição espacial de comprimento das fraturas (DOMENICO; SCHWARTZ, 1990; ODLING, 1997).

No contexto nacional, ambientes de terreno cristalino estão presentes nas regiões mais povoadas e de maior relevância econômica - no corredor Sul-Nordeste, paralelo à linha de 
costa (ANA, 2005), evidenciando a importância dos aquíferos fraturados na produção de água para atividades industriais e abastecimento público/privado (HIRATA et al., 2019). Entretanto, os conhecimentos teórico e prático, assim como as técnicas e as ferramentas para estudo e exploração desse meio geológico, ainda são pouco difundidos no Brasil, devido principalmente à complexidade e ao elevado valor da aplicação de técnicas avançadas de investigação, em especial quando há casos de contaminação em aquíferos fraturados.

Os trabalhos nacionais com foco em aquíferos fraturados ocorrem majoritariamente na esfera acadêmica, empregando de técnicas tradicionais às mais avançadas, mais comuns em trabalhos internacionais. 0 mapeamento geológico de detaIhe, a análise de lineamentos e a análise tectônica são as abordagens mais usuais, observadas em Fernandes et al. (2006), Fernandes et al. (2016), Fiume et al. (2020). Também é recorrente a utilização de ferramentas específicas de geofísica de poço, como em Monteiro (2016), Fanti et al. (2017), Barbosa (2019) e Fiume et al. (2020) e Pino et al. (2021).

Algumas das técnicas mais avançadas e especializadas, utilizadas especialmente em projetos de investigação de contaminação em aquíferos fraturados são: sondagens com recuperação de testemunhos e análise de contaminantes; utilização de liners para selagem de poços; utilização de obturadores de pressão para ensaios hidráulicos e amostragens discretas de água; e sistemas multiníveis para monitoramento e amostragem. Essas técnicas compõem a metodologia Discrete Fracture Network (PARKER, 2007), referência no estudo de aquíferos fraturados, e já aplicada de maneira pioneira no Brasil em rochas cristalinas com perfil de alteração por Bertolo (2017), Lojkasek-Lima (2018), Barbosa (2019) e Pino et al. (2021).

Com base nos trabalhos já realizados, observa-se a importância de uma fase inicial de investigação, previamente à introdução de métodos mais especializados, custosos e invasivos, quando é preciso caracterizar o aquífero de maneira integral. Dessa forma, a abordagem denominada top-down ("de cima para baixo") adequa-se a essa necessidade, ao considerar as variações nas propriedades hidráulicas do meio em diferentes escalas de observação (FERNANDES, 1997; ODLING, 1997; ROBINSON et al., 2008).

Para a aplicação da abordagem top-down, três técnicas tradicionais e não invasivas para o estudo do meio fraturado foram selecionadas, de menor para maior escala: (1) análise de lineamentos; (2) amostragem estrutural em afloramentos; e (3) levantamento geofísico pelo método de caminhamento elétrico.

Em escala regional, a determinação de trends estruturais por meio do traçado de lineamentos sobre fotografias aéreas ou modelos de terreno tem sido recorrente na caracterização de aquíferos fraturados (MABEE et al., 1994; FERNANDES; RUDOLPH, 2001; SANDER, 2007; WAHNFRIED, 2010; PINO, 2012).
Em escala local, o levantamento estrutural de campo é essencial em trabalhos com rochas cristalinas, como nos setores de mineração, construção civil e principalmente em estudos que abordam o aquífero fraturado. Uma das principais ferramentas utilizadas para amostragem e caracterização de pacotes rochosos fraturados é o método de scanlines, largamente aplicado em litologias diversas, como basaltos (FERNANDES; ROULEAU, 2008; FERNANDES et al., 2011), anortositos (Pino et al., 2011), gnaisses (FERNANDES et al., 2016; FIUME et al., 2018; PINO et al., 2021) e até mesmo rochas sedimentares fraturadas (CHESNAUX et al., 2009). A coleta e a análise desses dados viabilizam a definição e caracterização dos principais grupos de fraturas presentes nesses diferentes meios. São determinadas as propriedades intrínsecas às fraturas, que podem ser indicativas de sua potencialidade para o fluxo de água (ROULEAU; GALE, 1985; FERNANDES, 2008): natureza da descontinuidade (extensional, cisalhante), rugosidade, direção e mergulho, comprimento, ondulação, preenchimento e indicadores cinemáticos.

Por fim, a técnica geofísica de caminhamento elétrico tem sido utilizada para complementar a investigação estrutural de campo (MADRUCCl et al., 2005; RAYNER et al., 2007; WAHNFRIED, 2010; RATNAKUMARI et al., 2012). o caminhamento elétrico possibilita a localização de descontinuidades do substrato rochoso em escala de sítio, permitindo relacioná-las com a topografia do terreno e com estruturas observadas em afloramentos.

Dessa forma, o objetivo deste trabalho, ao aplicar as três técnicas selecionadas em um local contaminado, é reforçar o estabelecimento de uma metodologia para a investigação inicial do meio fraturado, que conjugue simplicidade com viabilidade econômica no contexto nacional, e que forneça dados fundamentais para otimizar a explotação de água subterrânea e aprimorar a investigação do transporte de contaminantes.

\section{2. ÁREA DE ESTUDO}

A metodologia proposta foi aplicada em uma área situada numa região entre as bacias de Resende e de Volta Redonda (RJ). De idade paleogênica, essas bacias estão inseridas no segmento central do Rift Continental do Sudeste do Brasil (RCSB), juntamente com as bacias de Taubaté e São Paulo (RICCOMINI, 1989). O RCSB, por sua vez, faz parte da Faixa Móvel Ribeira (HEILBRON et al., 2004). As unidades do embasamento, descritas abaixo, ocorrem como corpos alongados de direção NE-SW, de acordo com o trend regional da Faixa Ribeira; são formadas por complexos ortoderivados paleoproterozoicos, complexos paragnáissicos neoproterozoicos e suítes intrusivas neoproterozoicas e paleozoicas, inseridos nos domínios do Terreno Ocidental, Terreno Embu e Klippe Paraíba do Sul da Faixa Ribeira (Figura 1) (HEILBRON et al. 2000):

- Complexo Juiz de Fora: de idade paleoproterozoica, na área de estudo é formado por ortognaisses migmatíticos, de paragênese metamórfica em fácies granulito. As rochas granulíticas estão dispostas como escamas tec- 
tônicas, intercaladas com rochas da cobertura metassedimentar neoproterozoica, e são limitadas por zonas de cisalhamento.

- Grupo Paraíba do Sul: de idade neoproterozoica, corresponde à cobertura metassedimentar do Terreno Paraíba do Sul, que inclui litotipos metamorfizados em fácies anfibolito superior. Esse Grupo é formado por gnaisses bandados com variações composicionais que o subdividem em basal, mediano e superior.

- Complexo Embu: embasamento pré-cambriano paragnáissico, caracterizado como gnaisses e xistos pelíticos com intercalações de quartzito e rochas calcissilicáticas, metamorfizadas em fácies anfibolito, aflorantes na Serra da Bocaina, e sua vertente a norte, orientada para o Vale do Paraíba.

- Suítes intrusivas (Campo Alegre e Rio Turvo): segundo datações geocronológicas e fases de deformação, são definidos cinco pulsos ígneos intrusivos principais (entre 790 Ma e 480 Ma), responsáveis pela geração de inúmeros corpos granitoides, gerados durante a convergência neoproterozoico-eopaleozoica do segmento central da Faixa Ribeira.

Figura 1 - Mapa geológico simplificado do segmento central da Faixa Ribeira na região das bacias de Resende e Volta Redonda

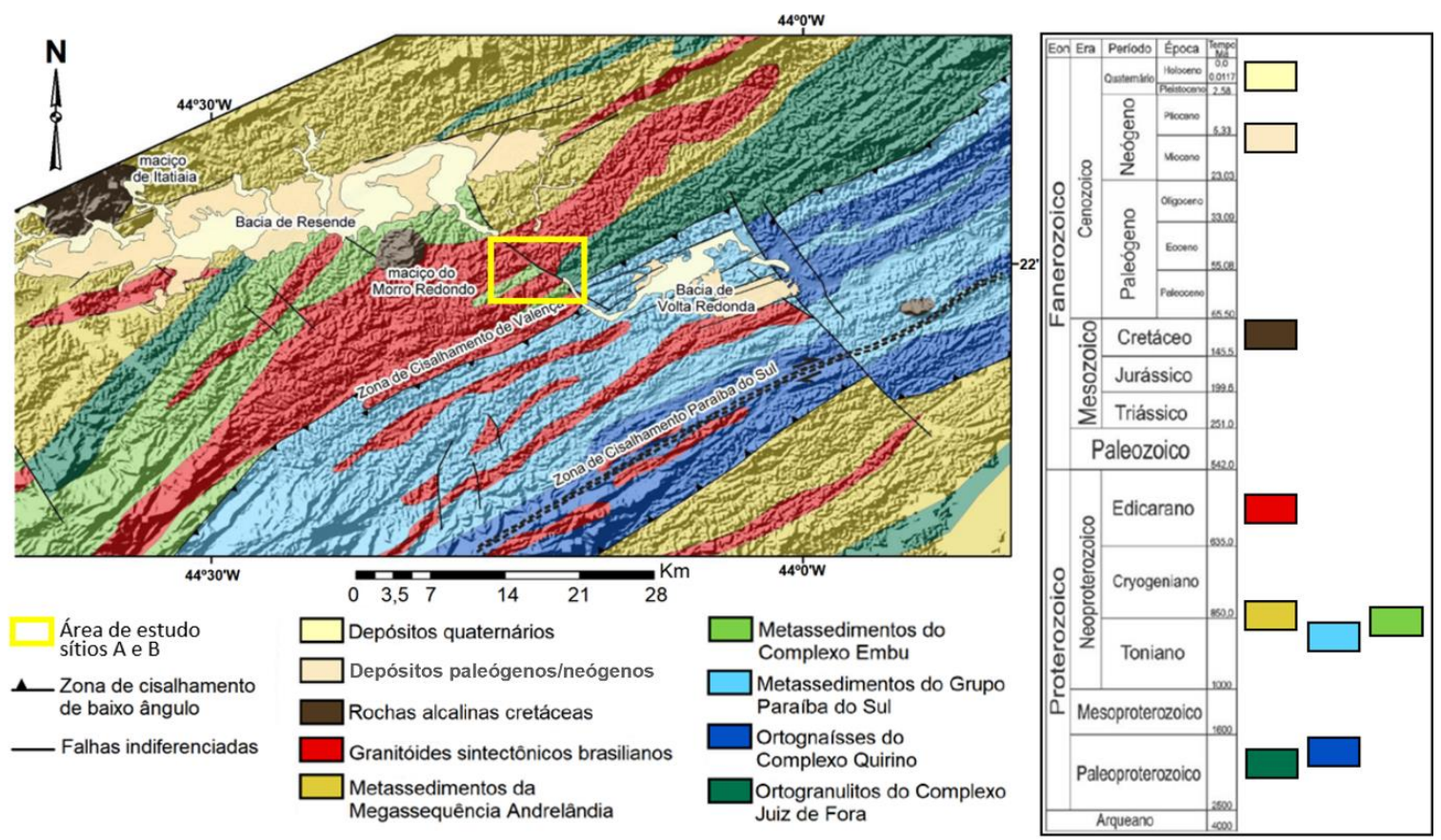

Fonte: Modificado de Heilbron et al. (2004).

A tectônica mais recente que afetou a região está relacionada às fases rúpteis do segmento central do RCSB (RICCOMINI et al., 2004). A fase inicial de distensão NW-SE, de idade paleógena, é responsável pela abertura, sedimentação e vulcanismo da Bacia de Volta Redonda (SANSON, 2006). Está associada a grandes e contínuos lineamentos com orientação NE-SW na bacia, os quais corresponderiam a zonas de cisaIhamento reativadas por um regime tectônico distencional posterior, e estariam associadas à gênese da Bacia de Volta Redonda (RICCOMINI et al., 2004; SANSON, 2006).

As duas fases seguintes são caracterizadas por regimes transcorrentes. Primeiro, a transcorrência sinistral E-W foi responsável pela formação de campos de falhas normais de direção NE-SW a NNE-SSW, falhas sinistrais normais e normais sinistrais NE-SW a NW-SE, e falhas normais dextrais e dextrais normais NNE-SSW e NNW-SSE (SANSON, 2006). Estas falhas afetam exclusivamente depósitos paleógenos. Segundo, a transcorrência dextral se manifesta em falhas normais WNW-ESE a NNW-SSE, falhas normais dextrais NE-SW, ENE-WSW, WNW-
ESE e NW-SE, e falhas sinistrais normais NNW-SSE a NNE-SSW (SANSON, 2006). Tais estruturas afetam depósitos sedimentares paleógenos e coberturas neógenas, não sendo observadas em depósitos holocênicos fluviais e alúvio-coluviais. Por fim, um regime distensivo NW-SE gerou falhas normais NNESSW, NE-SW e ENE-WSW, afetando desde os depósitos paleógenos até os sedimentos holocênicos (SANSON, 2006).

Hidrogeologicamente, a área de estudo está localizada no contexto da Bacia Hidrogeológica de Resende, a qual compreende três unidades aquíferas (CASTRO, 2000): (i) aquífero sedimentar livre, caracterizado por depósitos quaternários; (ii) aquífero sedimentar multicamadas, composto por unidades sedimentares paleógenas a neógenas da Bacia Sedimentar de Resende; e (iii) aquífero cristalino fraturado, formado por rochas do embasamento. A precipitação pluviométrica é a principal fonte de recarga do aquífero livre, o qual, por sua vez, recarrega os dois aquíferos subjacentes.

O aquífero multicamadas é bastante extenso lateralmente, e 
embora seja significativamente heterogêneo litologicamente, é o mais explorado para abastecimento de água (CASTRO, 2000). Os valores de capacidade específica mais elevados estão associados a poços localizados nas proximidades de lineamentos de direção NE-ENE, relação também observada para poços que captam água do aquífero cristalino (ALBUQUERQUE, 2001).

\section{Metodologia}

Foi utilizada a investigação estrutural em diferentes escalas em um processo top-down, segundo o qual se inicia o estudo de uma escala menor (p.e., análise regional) para uma escala maior (p.e., estudo de afloramentos) (ROBINSON et al., 2008). Para isso, três técnicas específicas foram aplicadas na seguinte ordem: (1) análise de lineamentos em escala regional; (2) amostragens estruturais em escala local; e (3) levantamento geofísico em escala local, com foco no sítio investigado. Cada abordagem é explicada em detalhe a seguir.

\subsection{Análise de lineamentos}

A análise de lineamentos foi empregada para avaliar preliminarmente e de maneira remota as principais tendências estruturais (trends) da região estudada. Para isso, foi utilizado um modelo digital de elevação (MDE) com pixel de tamanho $20 \times 20 \mathrm{~m}^{2}$ (IBGE, 2017), que consiste em um mapa do relevo gerado por satélite ou fotografia aérea. A experiência neste trabalho e em estudos prévios (FERNANDES; RUDOLPH, 2001; PINO, 2012; FERNANDES et al., 2016; FIUME et al., 2018) indica que a escala do MDE deve ser preferencialmente maior que 1:25.000, sendo idealmente 1:10.000 ou superior.

Para o tratamento do MDE e interpretação de lineamentos, foram utilizados os programas de processamento geoespacial ArcMap e QGIS. A principal ferramenta utilizada nesses programas é denominada hillshade, que permite simular o sombreamento do $\mathrm{MDE}$, ressaltando as formas de relevo, com ângulo vertical de $45^{\circ}$ para a incidência de luz. A partir do MDE original, dois MDEs secundários foram gerados, com direções perpendiculares de incidência de luz: (1) incidência de luz a $45^{\circ}$ (nordeste), ressaltando estruturas com direção NW-SE; e (2) incidência de luz a $315^{\circ}$ (noroeste), ressaltando estruturas com direção NE-SW. A escolha dos ângulos deveu-se à orientação das principais estruturas regionais reportadas na literatura (RICCOMINI et al., 2004; SANSON, 2006).

Em seguida, todos os lineamentos representativos de feições observadas nos dois MDEs foram traçados manualmente. A fim de assegurar a identificação de estruturas independentemente de sua orientação espacial, o processo de traçado é realizado sempre em uma mesma escala (neste caso, fixada em 1:25.000, em função do processamento fotométrico analítico para obtenção dos MDEs feito por IBGE, 2017), não havendo variação por zoom, com constante alternância entre as duas incidências de luz $\left(45^{\circ}\right.$ e $\left.315^{\circ}\right)$ durante o processo.

Após o traçado de todos os lineamentos observados, um diagrama de frequência do tipo roseta foi gerado e a direção dos lineamentos foi utilizada como critério de discretização em categorias, conforme proposto por Negrão (2014). Ambos os recursos facilitam a visualização dos diferentes trends estruturais presentes. Os lineamentos foram divididos em seis intervalos: (1) NNE: N01E - N2OE; (2) NE: N21E - N70E; (3) ENE: N71E - N89E; (4) NNW: N01W - N20W; (5) NW: N21W N70W; (6) WNW: N71W - N89W.

\subsection{Levantamento estrutural de campo}

A amostragem estrutural foi realizada pontualmente e por meio sistemático com linhas de levantamento (scanlines). 0 método de scanlines consiste na projeção de uma linha horizontal (representada por uma fita métrica) sobre o afloramento, perpendicularmente à direção de maior mergulho, a partir da qual são medidas e descritas todas as descontinuidades que a interceptam (Figura 2). Foram analisados afloramentos de pedreira com paredes planas, limpas e relativamente grandes em relação ao tamanho e ao espaçamento das descontinuidades observadas, conforme os parâmetros considerados mais adequados para aplicação da técnica (Priest, 1993).

Figura 2 - Amostragem sistemática de fraturas por meio do método de scanline em afloramento de corte subvertical

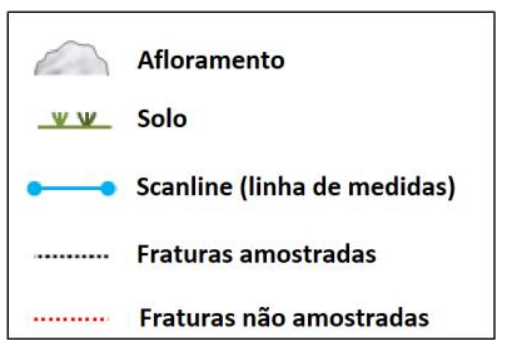

Fonte: Adaptado de: Pino et al. (2019).

0 processo de amostragem dos afloramentos foi iniciado pelo registro das coordenadas (início e fim da scanline), situação da rocha (fresca, intemperizada), dimensões do afloramento, atitude da parede, comprimento da scanline e, após o posicionamento da fita métrica, registro fotográfico para conferências visuais posteriores. A partir de uma das extremidades da

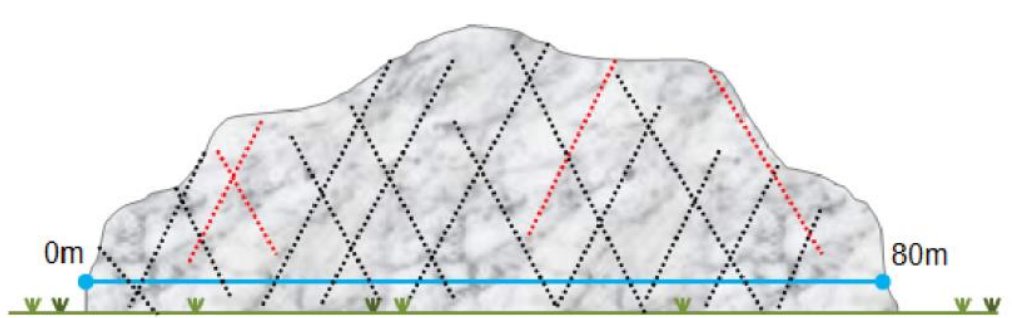

trena, todas as descontinuidades que a interceptam foram localizadas e descritas de forma discreta.

Em formulário de campo, registrou-se, para cada descontinuidade: localização na extensão da scanline, evitando descontinuidades não naturais; atitude; presença e atitude de estrias, 
para entender o tipo de falhamento; tipo de estrutura (junta, falha, zona de falha); comprimento; forma (plana, curva, ondulada); rugosidade, classificação visual de acordo com o Coeficiente de Rugosidade de Junta (JRC) (Barton e Choubey, 1977); alteração; revestimento; preenchimento; tipo de terminação (em outra fratura, em rocha, oculta); presença de água e/ou de vegetação. A relação de parâmetros baseou-se nas discussões apresentadas por Fernandes et al. (2016) e Pino et al. (2019), com adaptações quando necessário. Para o meIhor entendimento da correlação entre os diferentes grupos de fraturas, desenhos manuais dos afloramentos sobre fotos digitais foram elaborados em campo, buscando representar ao menos uma fratura de cada um dos grupos identificados nos afloramentos.

Priest (1993) enfatiza que não há padrões universais para a aplicação do método de scanline, recomendando, quando pertinente, a adição de parâmetros de amostragem, com o objetivo de adequá-lo a condições singulares de corpos rochosos ou prover dados específicos a um modelo de pesquisa. Por se tratar de um trabalho de Geologia Estrutural aplicada à Hidrogeologia, foram contemplados parâmetros complementares: direção e mergulho de estrias de cisalhamento, cor e espessura de alterações e preenchimentos, presença de água e/ou vegetação, indicativos indiretos de abertura hidráulica.

Após o levantamento em campo, o tratamento dos dados estruturais foi realizado, incluindo a correção do viés de orientação (TERZAGHI, 1965). Esse viés ocorre devido ao ângulo formado entre as fraturas e o plano do afloramento, de modo que a observação direta das estruturas, na maioria dos casos, não representa adequadamente a proporção de descontinuidades de diferentes grupos de fraturas, e subestima o espaçamento real entre fraturas de um mesmo grupo. Esta correção pode ser feita diretamente a partir de algumas das ferramentas de geração de estereograma, assim como por meio de fórmulas em planilhas eletrônicas, como descrito e aplicado por Pino et al. (2019).

A partir da correção das densidades relativas de fraturas, os valores reais de espaçamento das descontinuidades de um mesmo grupo foram calculados. Estes dados permitiram, por fim, gerar estereogramas com contornos de frequência, utilizando o software Stereonet, que indicam os grupos de fraturas existentes na área de estudo.

\subsection{Caminhamento elétrico}

Este método geofísico de superfície foi empregado com o objetivo de obter, de forma não invasiva, informações complementares sobre o substrato rochoso, como profundidade do embasamento, orientação de possíveis estruturas, espessura do pacote sedimentar, presença de matacões e nível d'água. A identificação de descontinuidades é realizada por meio de medidas da eletrorresistividade dos materiais (KELLER; FRISCHKNECHT, 1966). São utilizados eletrodos (barras de aço inox com cerca de $50 \mathrm{~cm}$ de comprimento) cravados no solo ao longo do perfil e conectados a um resistivímetro. As extensões das linhas de caminhamento foram definidas em função da área livre em superfície e da profundidade analisada, uma vez que a profundidade alcançada pelo método tem relação com o comprimento das linhas.

A técnica de caminhamento elétrico empregada foi com o arranjo dipolo-dipolo e o equipamento utilizado foi o SYSCAL Pro com 10 canais e 48 eletrodos, e conexão por cabo multifilar com 24 vias. Para cada posição de medição, um par de eletrodos $\mathrm{AB}$ conectado a um amperímetro foi utilizado para gerar uma corrente elétrica, e um segundo par de eletrodos $\mathrm{MN}$, conectado a um voltímetro, mediu a diferença de potencial gerada pelo circuito de corrente, calculando assim a eletrorresistividade de um ponto em subsuperfície. Após o registro, os dados foram tratados e os pontos de medida foram interpolados por meio do software RES2DINV para gerar perfis contínuos de resistividade elétrica, através do método de elementos finitos e otimização de mínimos quadrados não linear com restrição de suavidade.

\section{Resultados}

A aplicação das técnicas descritas possibilitou a produção de mapas e perfis para a caracterização estrutural da área de estudo. Os dados obtidos nas três etapas de levantamento são apresentados e discutidos a seguir. Por fim, discutem-se relações causais entre as estruturas observadas e os eventos neotectônicos descritos na literatura para a região.

\subsection{Estruturas regionais}

Os principais produtos dessa etapa são mapas de lineamentos, de escala regional e de escala local de sítio. Para este estudo de caso, foi confeccionado um mapa abrangendo uma área de aproximadamente $300 \mathrm{~km}^{2}$ (Figura 3), utilizado para a determinação dos grupos de lineamentos e para gerar a roseta de frequência com os trends estruturais da região, que tem como peso o número absoluto e o comprimento das estruturas (TOMASI; ROISENBERG, 2019). Os lineamentos foram divididos em seis grupos de orientação. Dois trends estruturais destacam-se na roseta de frequência: (1) NW-SE (Figura 3 , em vermelho), lineamentos de pequeno porte e numerosos; e (2) NE-SW/ENE-WSW (Figura 3, em verde e rosa), lineamentos de médio a longo porte e menos numerosos, que cortam os lineamentos NW-SE. 
Figura 3 - Classificação de lineamentos em escala regional (esquerda), com destaque aos dois trends principais indicados na roseta de frequência (direita, abaixo): NW-SE e NE-SW/ENE-WSW

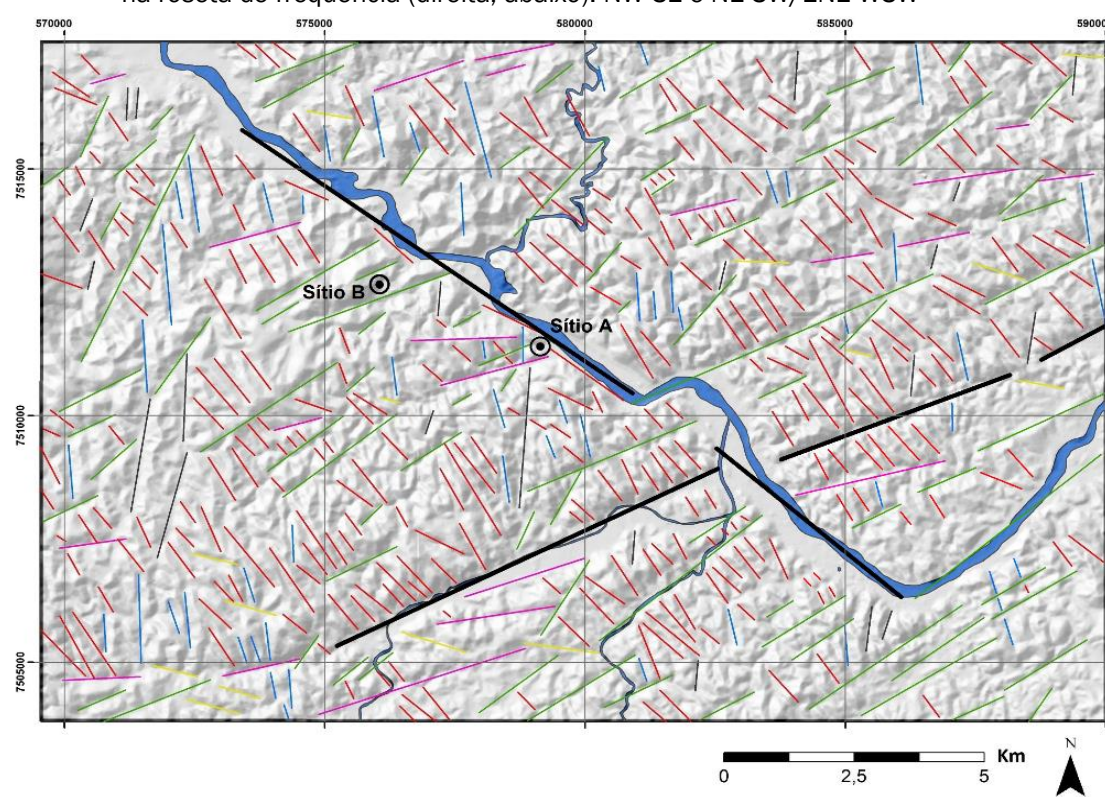

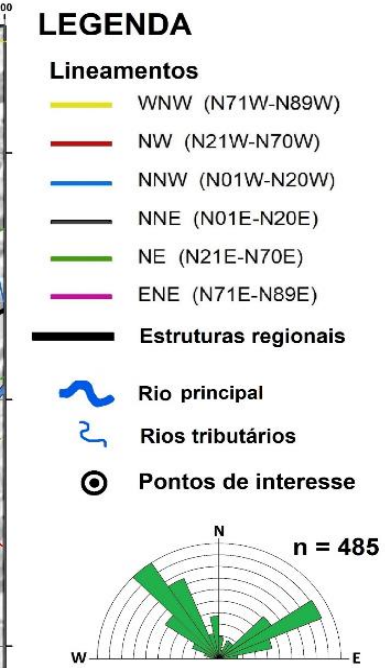

Geographic Coordinate System: SIRGAS 2000 Database: Project RJ25 - IBGE (2016)

Fonte: os autores.

Para detalhar a área foco e correlacionar as estruturas regionais com as observações locais, os lineamentos também foram traçados em um mapa de maior detalhe (Figura 4), que abrange uma área de aproximadamente $40 \mathrm{~km}^{2}$. Os métodos de amostragem estrutural e geofísica foram empregados nos sítios A e B (pontos de interesse na Figura 3; retângulos na Figura 4). No mapa de detalhe, observa-se que, embora os dois trends principais identificados anteriormente ainda sejam facilmente identificados, as estruturas do grupo NW-SE aparecem mais difusas (Figura 4).

Figura 4 - Classificação de lineamentos em escala local, destacando-se as áreas de interesse A e B, nas quais também foram realizados os levantamentos locais de campo.

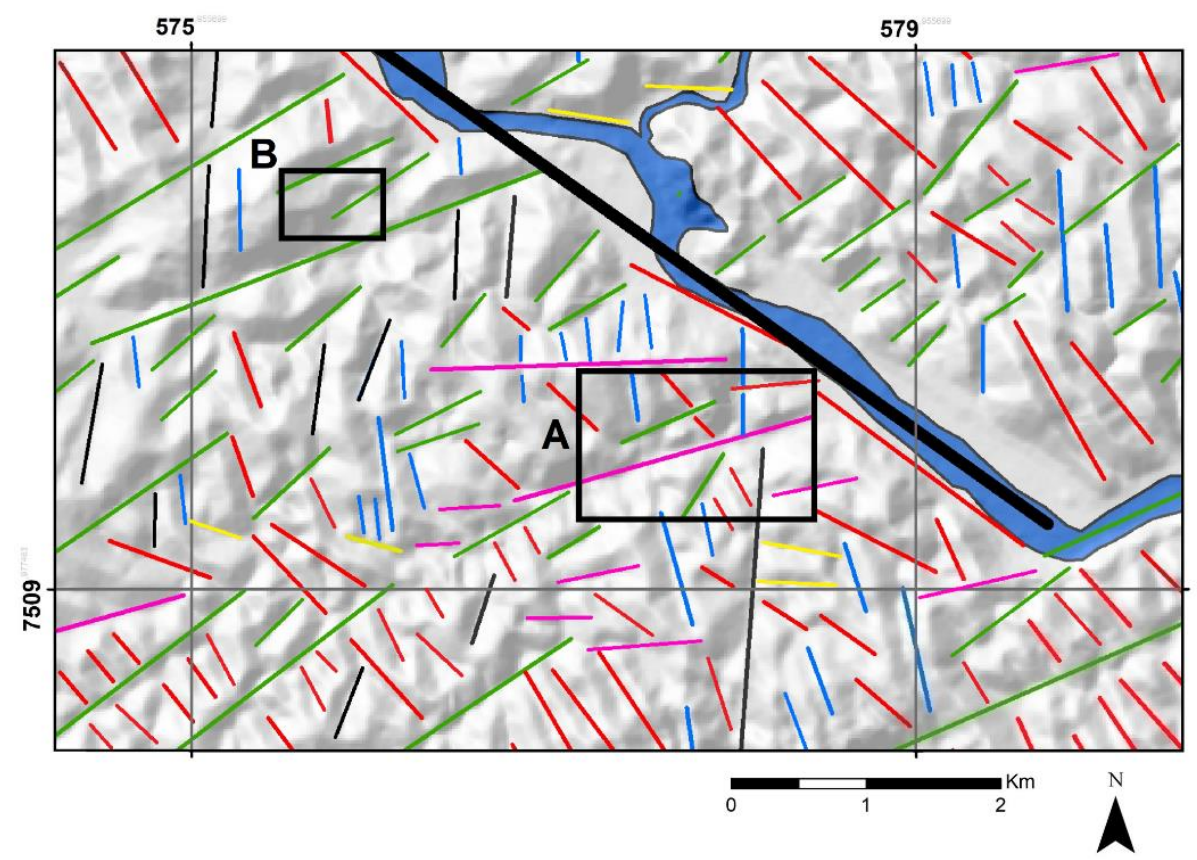

\section{LEGENDA}
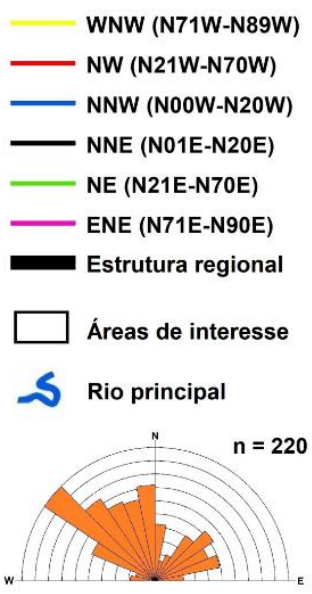

Sístema de Coordenadas Geográficos SIRGAS 2000 Projeto RJ25 - IBGE (2016)

Fonte: os autores. 


\subsection{Estruturas locais}

Os dados estruturais foram coletados no sítio A por meio de amostragens pontuais em seis afloramentos, devido à inexistência de afloramentos contínuos de rocha, totalizando 49 estruturas. Por sua vez, no sítio B foram realizadas 17 scanlines, totalizando 179 estruturas amostradas em cerca de $410 \mathrm{~m}$ de linhas de levantamento (Figura 5). Os dados coletados em scanlines foram corrigidos pelo método de Terzaghi (1965) e são apresentados em estereogramas, evidenciando três grupos principais de fraturas (Figura 6).

Figura 5 - A - Fraturas observadas em afloramento do Sítio B durante amostragem por scaline; B - Fraturas do Grupo 1 (sub-horizontais) vertendo água, observadas no Sítio B; C - Fraturas dos Grupos 3 (ENE-WSW) e 2 (NW-SE), à esquerda e à direita, respectivamente, observadas no sítio B; D - Medida pontual de estruturas em afloramento intemperizado no Sítio A
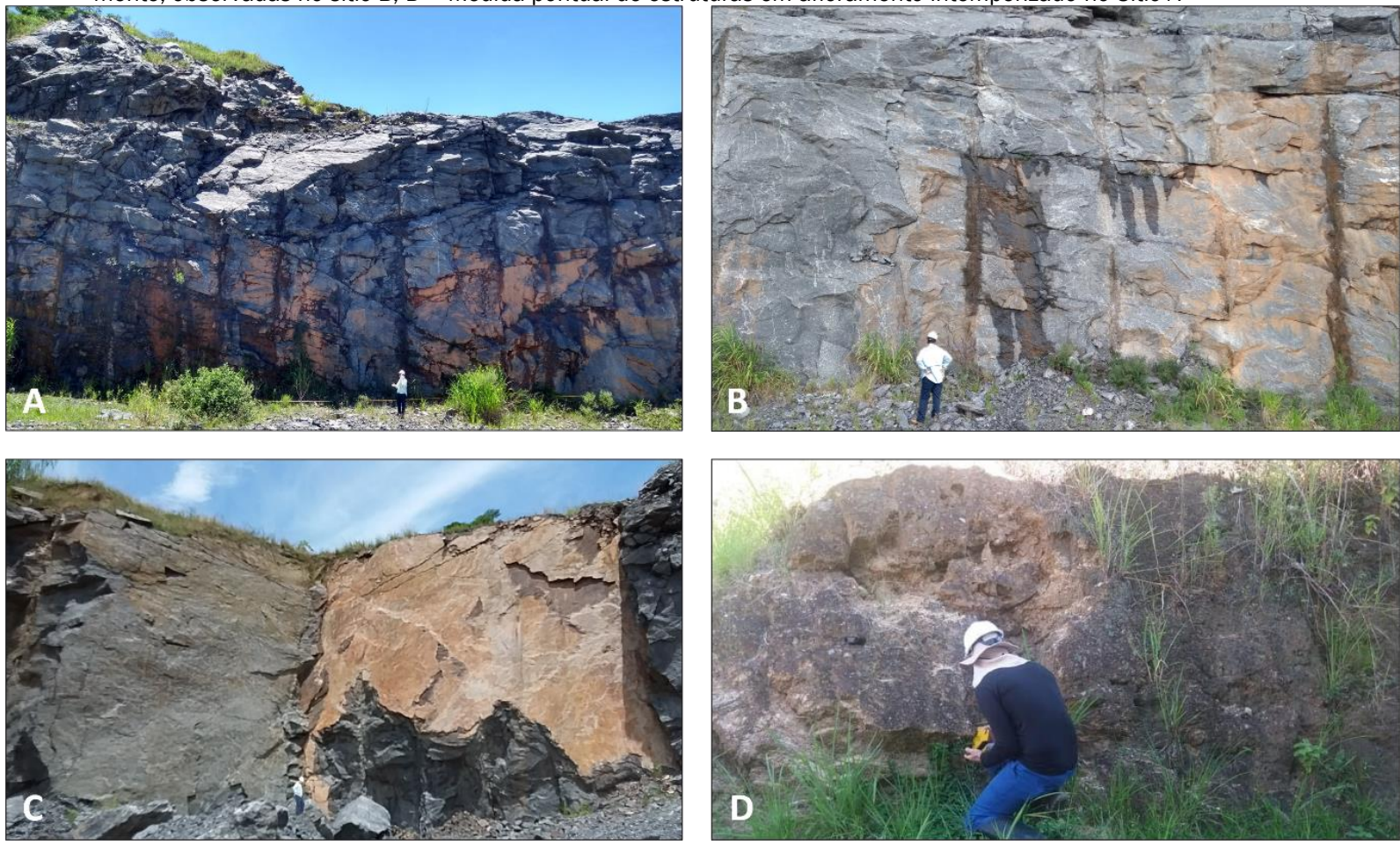

Fonte: os autores.

Diante das semelhanças litológico-estruturais observadas em campo, a exemplo de estrutura, composição mineral das rochas (bandamento composicional félsico e máfico, com quartzo e feldspato grossos, biotita fina, anfibólio e piroxênio), preenchimento de fraturas por veios de quartzo, revestimento de fraturas por filmes de quartzo, e a proximidade espacial, foi definido que as rochas presentes nos sítios A e B fazem parte da mesma unidade litológica, correspondente ao Complexo Juiz de Fora. Por apresentarem características semelhantes, acredita-se que pertençam a um mesmo domínio tectônico.

O levantamento feito por meio das scanlines no sítio B identificou três grupos principais de fraturas (sintetizados na Tabela 1): (1) horizontais, (2) NW-SE de alto ângulo de mergulho, e (3) ENE-WSW de alto ângulo de mergulho. Os dois últimos grupos são correlacionáveis aos lineamentos indicados em vermelho e rosa/verde na Figura 4, respectivamente. Por meio da amostragem pontual no sítio $A$, foi observada a recorrência do Grupo 2 - NW-SE (lineamentos em vermelho na Figura 4) e identificado um grupo secundário com poucas estruturas representativas, de orientação NNW-SSE e alto ângulo de mergulho, correlacionado aos lineamentos em azul na Figura 4. 
Figura 6 - Diagramas de densidade dos grupos de fraturas identificados nos Sítios A e B, e suas relações com os Grupos de lineamentos da Figura 3

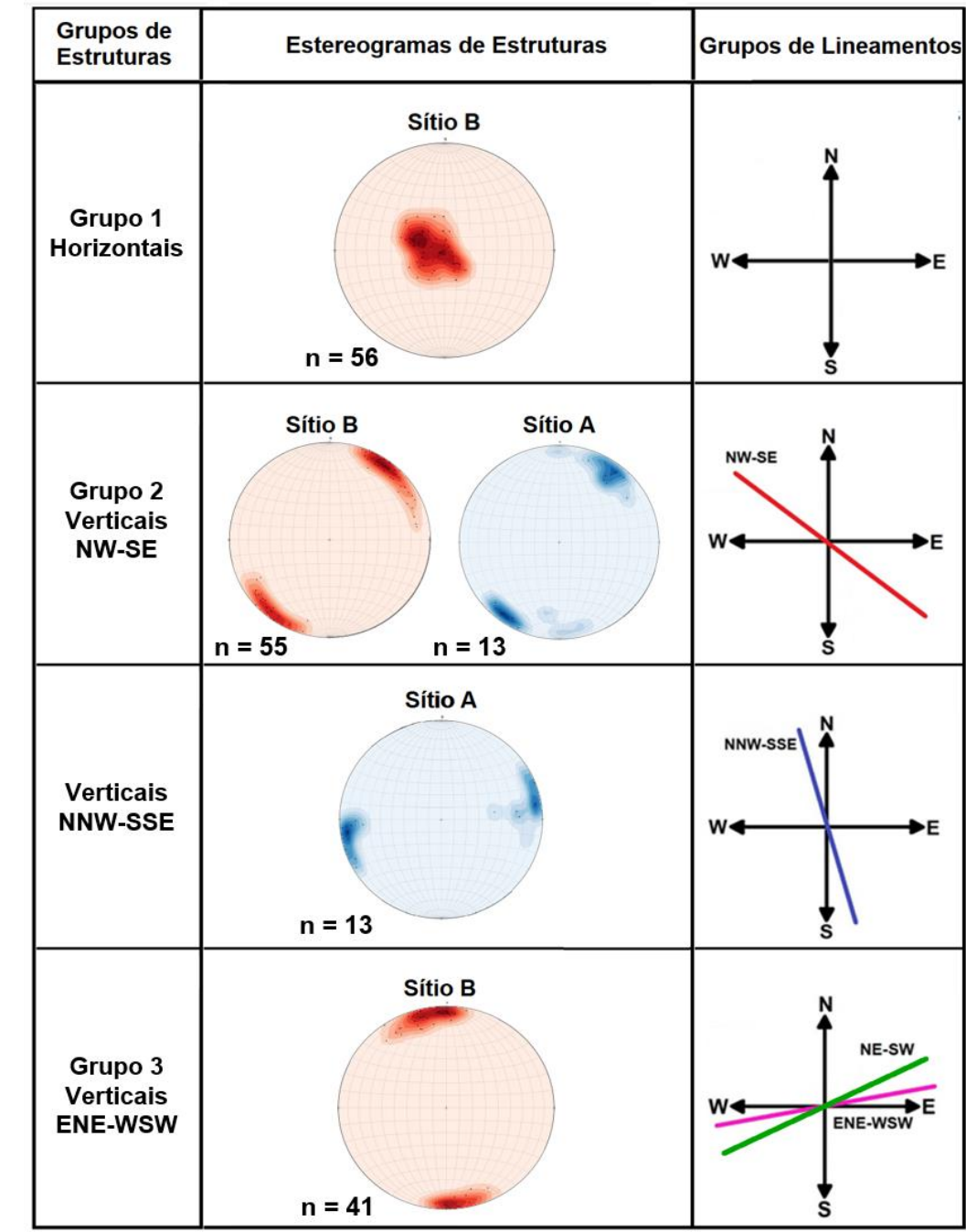

Fonte: os autores.

Tabela 1 - Grupos de fraturas identificados nos sítios estudados

\begin{tabular}{|c|c|c|c|}
\hline Grupo & Direção & Mergulho & Caracterização \\
\hline $\begin{array}{c}1(\mathrm{H}) \\
56 \text { fraturas }\end{array}$ & Dispersas & $\begin{array}{l}\text { Média } \\
19^{\circ}\end{array}$ & $\begin{array}{l}\text { - Espaçamento: média 1,36 metro } \\
\text { - Morfologia: planas a curvas } \\
\text { - Comprimento: média de } 6 \text { metros } \\
\text { - Características: maior número de fraturas } \\
\text { com água e/ou vegetação }\end{array}$ \\
\hline $\begin{array}{c}2 \text { (NW-SE) } \\
55 \text { fraturas }\end{array}$ & $\begin{array}{l}\text { N09-75W } \\
\text { Média } \\
\text { N42W }\end{array}$ & $\begin{array}{l}68^{\circ}-90^{\circ} \text { para } \\
\text { NE ou SW } \\
\text { Média } \\
81^{\circ}\end{array}$ & $\begin{array}{l}\text { - Espaçamento: média de 1,04 metro } \\
\text { - Morfologia: planas, poucas onduladas } \\
\text { - Comprimento: média de 8,55 metros } \\
\text { - Características: veios de quartzo, associação } \\
\text { de veios à óxidos }\end{array}$ \\
\hline $\begin{array}{c}3 \text { (ENE-WSW) } \\
41 \text { fraturas }\end{array}$ & $\begin{array}{l}\text { N79-90W } \\
\text { e N50-90W }\end{array}$ & $\begin{array}{l}69^{\circ}-89^{\circ} \text { para } \\
\text { NNW ou SSE }\end{array}$ & $\begin{array}{l}\text { - Espaçamento: média de 4,94 metros } \\
\text { - Morfologia: planas, poucas onduladas } \\
\text { - Comprimento: média de 8,04 metros } \\
\text { - Características: veios de quartzo, intrusão por } \\
\text { diques de lamprófiro }\end{array}$ \\
\hline
\end{tabular}

Fonte: os autores.

Obs.: A notação utilizada para determinar a direção das fraturas foi a Regra da Mão Direita. 


\subsection{Estruturas em profundidade}

Os perfis gerados pelo caminhamento elétrico possibilitaram a identificação detalhada de feições geológicas, como: (i) corpos resistivos de pequenas dimensões (2 a $6 \mathrm{~m}$ ) de formato esferoidal, representando matacões; (ii) porções menos resistivas, sugerindo a presença de zonas de falhas ou de fraturamento com presença de água; e (iii) interações entre diferentes estruturas. No caso estudado, os perfis mais longos, de 500 a $800 \mathrm{~m}$, atingiram profundidades de até $80 \mathrm{~m}$, permitindo observar as porções de rochas intemperizadas e rochas sãs que compõem o aquífero fraturado.

No sítio A, foram realizadas 4 linhas de caminhamento geofísico, orientadas aproximadamente N-S (linhas L2 e M2) e E-W (linhas L1 e M1), paralelas a grandes lineamentos (Figura 7). A interpretação dos perfis de resistividade resultantes do caminhamento elétrico é feita com base nas diferenças entre os valores obtidos para cada ponto e valores de resistividade elétrica estabelecidos na literatura para diferentes materiais (TELFORD et al., 1990).

Figura 7 - Sítio A com a localização das linhas de caminhamento elétrico, dos lineamentos e da seção A-A' (descrita na Figura 10)

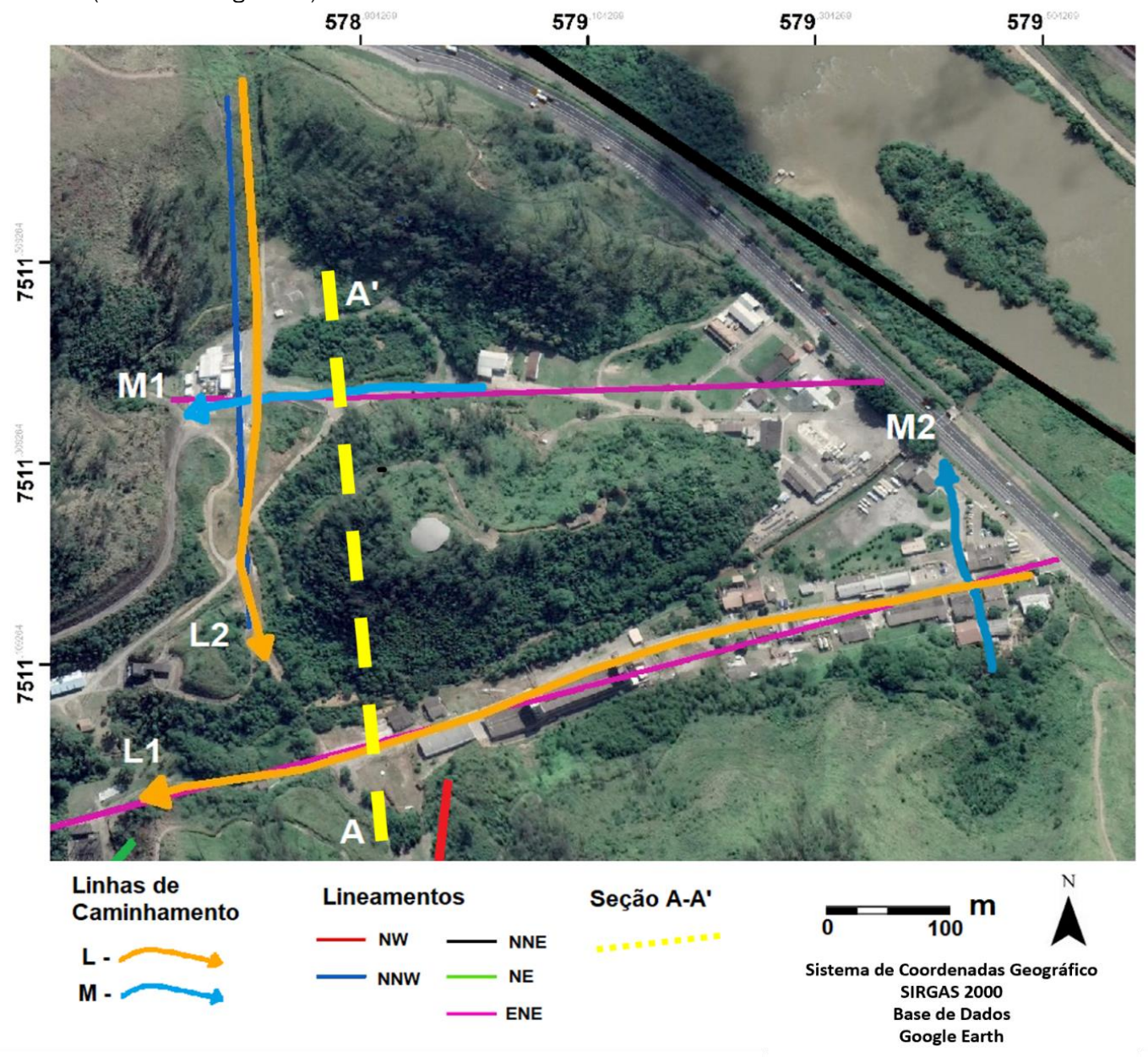

Fonte: os autores.

O perfil L1 (Figura 8a), localizado na porção sul da área A, tem extensão de $800 \mathrm{~m}$ e seu traçado coincide com um dos lineamentos ENE-WSW (Figura 7, em rosa). Apresenta predominância de valores de baixa eletrorresistividade (Figura 8a, em tons de azul) até profundidades abaixo dos $70 \mathrm{~m}$. Esses valores baixos são relacionados à presença de água, e foram aqui interpretados como uma zona de fraturamento com espessamento do manto de intemperismo, o que é corroborado pelo posicionamento do perfil L1 sobre um lineamento expressivo. 
Figura 8 - Perfis eletrorresistivos L1 (a), L2 (b), M1 (c) e M2 (d)
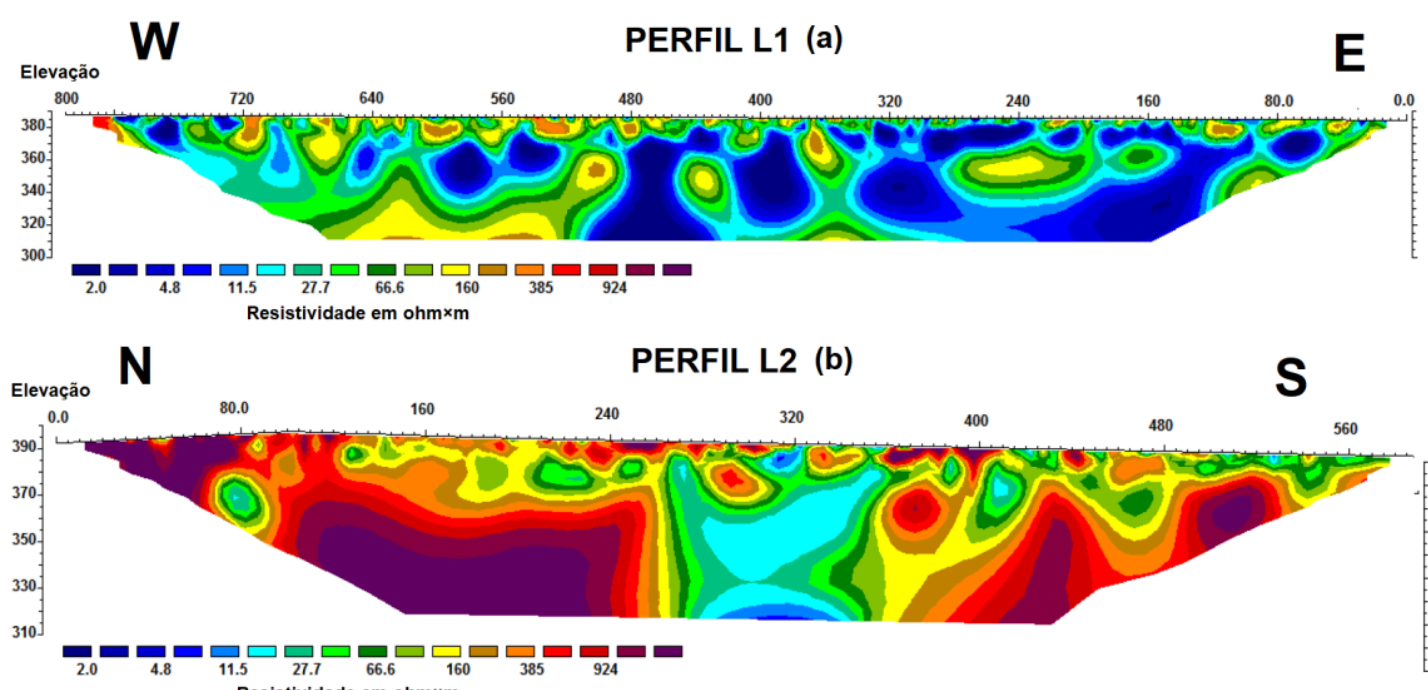

W

PERFIL M1 (c)

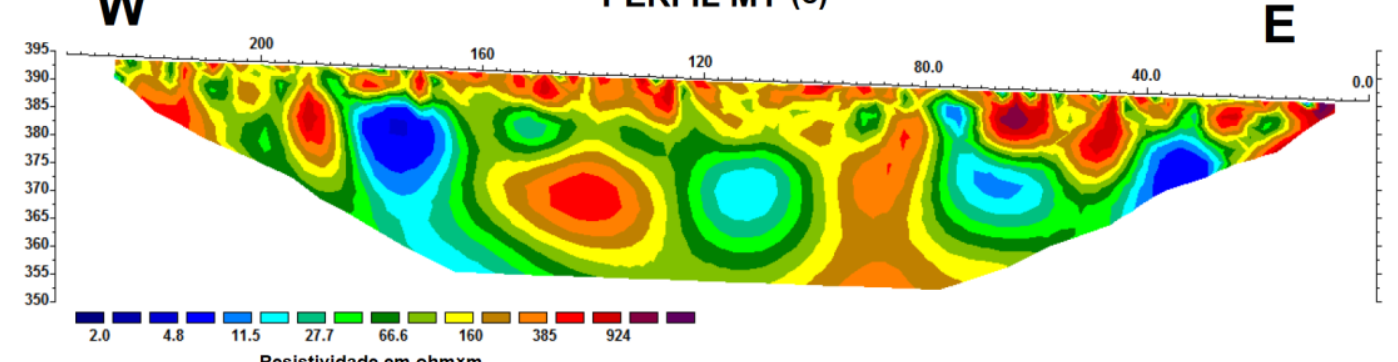

PERFIL M2 (d)

S

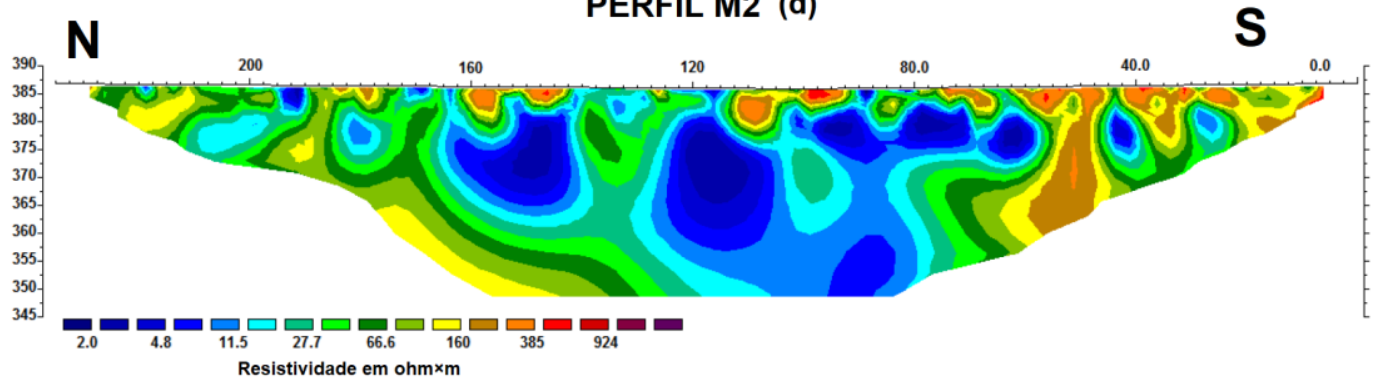

Fonte: os autores.

O perfil L2 (Figura 8b) está localizado na porção oeste da área A e tem extensão de $560 \mathrm{~m}$. Em sua porção central é observada uma zona de baixa eletrorresistividade, com cerca de $100 \mathrm{~m}$ de largura que atinge profundidades inferiores a $80 \mathrm{~m}$. Essa zona coincide com a intersecção do perfil L2 com um lineamento ENE-WSW (em rosa), e é interpretada como uma zona de fraturamento com maior espessamento do manto de intemperismo, favorável à circulação de água subterrânea.

0 perfil M1 (Figura 8c) tem extensão de 220 m, e cruza o perfil L2. Destaca-se uma estrutura em aproximadamente $175 \mathrm{~m}$ do perfil a partir de leste, com baixos valores de eletrorresistividade. Essa estrutura é interpretada como uma zona de baixa eletrorresistividade correlacionada ao lineamento de direção $\mathrm{N}-\mathrm{S}$ (azul), paralelo ao perfil de caminhamento elétrico L2, possivelmente uma zona fraturada com maior presença de água (observada também no centro do perfil L2, Figura 8b). Embora não tenham sido observadas em superfície outras estruturas relacionadas ao perfil $\mathrm{M} 1$, suas demais zonas de baixa eletrorresistividade em profundidade também podem estar relacionadas ao fluxo de água subterrânea.

0 perfil M2 (Figura 8d) tem extensão de $230 \mathrm{~m}$ e é cortado pelo perfil L1 em sua porção central. Entre 80 e $120 \mathrm{~m}$ a partir de sul, ocorrem baixos valores de eletrorresistividade, coincidentes com a intersecção com o perfil L1 e com um lineamento ENE-WSW (rosa), possivelmente relacionados à zona de fraturamento sugerida para o perfil L1.

\section{DISCUSSÃO}

A aplicação das três técnicas se mostrou adequada ao cenário do caso exposto, com potencial de replicação em localidades com semelhante arcabouço geológico e padrão de ocupação: 
regiões pouco urbanizadas, com relativa abundância de exposições de rocha fresca e áreas livres para a locação das linhas de caminhamento elétrico.

No que se refere à técnica geofísica, em áreas mais urbanizadas, a presença de vias asfaltadas dificulta a cravação dos eletrodos. Além disso, a eventual presença de infraestrutura subsuperficial, como tubulação metálica de redes de abastecimento e redes elétricas enterradas interfere nos resultados, alterando o caminho da corrente elétrica imprimida. Nesse cenário, técnicas como sondagens, geofísica de poço e sísmica de refração podem eventualmente ser mais adequadas (MONTEIRO, 2016; FANTI et al., 2017; FIUME et al., 2020; PINO et al., 2021). Embora a sísmica não permita uma diferenciação tão clara dos materiais como o método elétrico, e a geofísica de poço seja lateralmente mais restrita, essas técnicas podem fornecer dados importantes para a interpretação das propriedades do aquífero fraturado.

A análise de lineamentos possibilitou a identificação dos principais trends estruturais da região, NW-SE e NE-SW/ENEWSW. A técnica revelou ser de simples e robusta aplicação. $O$ levantamento estrutural possibilitou a identificação dos grupos de fraturas, informação considerada de relevância no estudo de aquíferos fraturados. A amostragem em campo e o subsequente tratamento dos dados foram as etapas que de- mandaram maiores esforços logísticos em termos de tempo e de recursos humanos. São consideradas as principais atividades no processo de caracterização estrutural e que podem apresentar as maiores limitações, pois dependem da existência de afloramentos de rocha fresca com paredes extensas, dispostos com certa abrangência espacial e variação de orientação, a fim de melhor representar estruturalmente o aquífero fraturado.

O caminhamento elétrico possibilitou o detalhamento em grande escala do substrato rochoso, indicando as posições e dimensões de zonas menos resistivas. 0 elevado grau de detalhamento dos perfis geofísicos permite sua aplicação também em estudos de contaminação, possibilitando indicar pontos de interesse para a locação de poços de monitoramento para o meio fraturado, uma vez conhecida a localização das áreas fontes de contaminação potencial.

De maneira geral, os três métodos apresentaram ótima correlação de dados, e a abordagem top-down permitiu compreender como as características geométricas da rede de fraturas do aquífero, observadas em menor escala, se manifestam também em maior escala. A partir dos grupos de estruturas observados na área do sítio $B$, foi elaborado um modelo estrutural conceitual 3D em escala local (Figura 9).

Figura 9 - Bloco diagrama com o modelo conceitual de disposição espacial dos três grupos de fraturas identificados nas rochas cristalinas do embasamento para o sítio $\mathrm{B}$, a partir da análise de lineamentos e da amostragem estrutural por scanlines

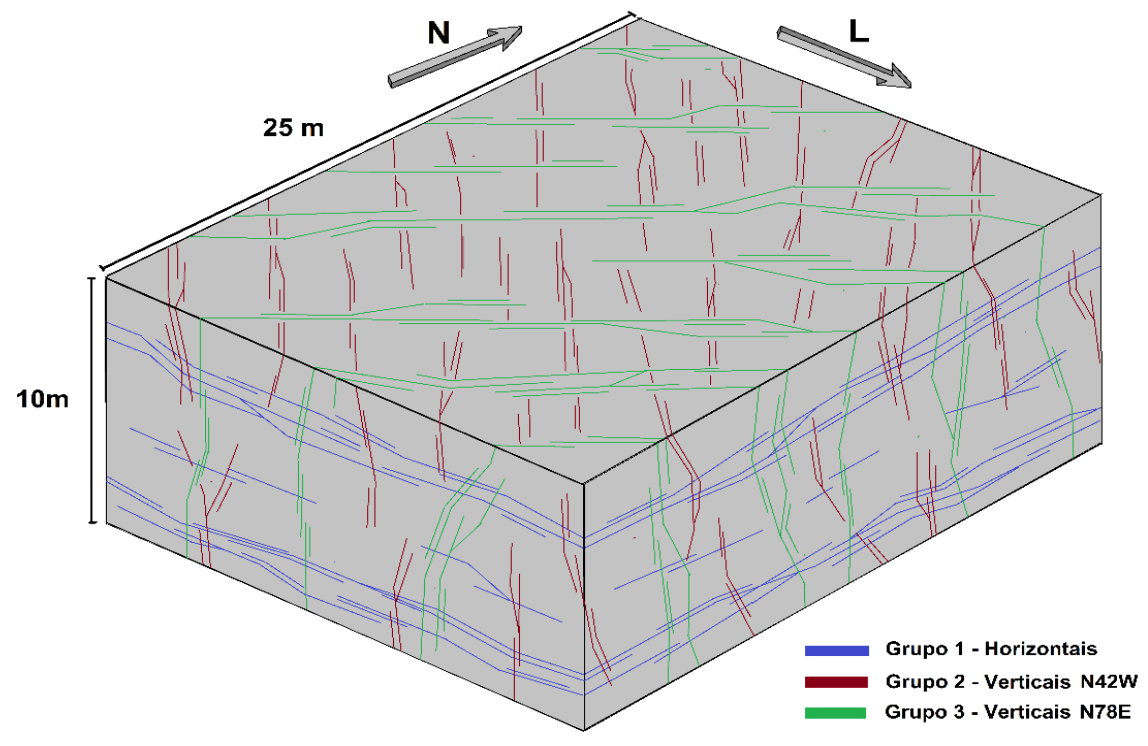

Fonte: os autores.

Combinando o modelo estrutural proposto com os dados de profundidade obtidos a partir da investigação geofísica no sítio A, foi desenvolvida uma seção transversal A-A', representativa do modelo conceitual geral para a área (Figura 10). A divisão dos materiais geológicos em solo de alteração, rocha alterada mole, rocha alterada dura e rocha fresca segue o modelo de intemperismo proposto por Vaz \& Gurgueira (2018). 
Figura 10 - Seção A-A', representativa do substrato rochoso e das estruturas observadas pelo caminhamento elétrico no sítio A. Destaque ao espessamento do manto de intemperismo nas áreas coincidentes com lineamentos (Perfis L1 e M1)

Cota (m) A (S)

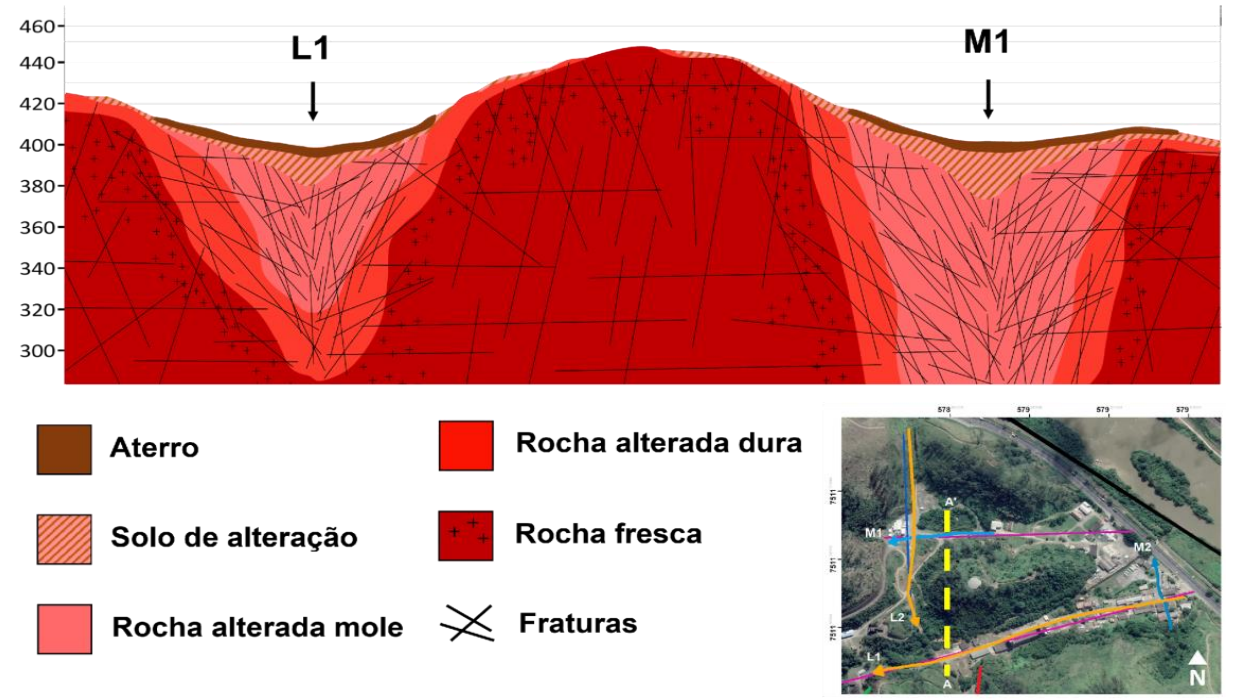

Fonte: os autores.

A existência de zonas de rochas com intemperismo acentuado coincide com zonas de adensamento de fraturas, que se manifestam na topografia como lineamentos, que por sua vez, sugerem caminhos preferenciais de fluxo de água subterrânea, corroborado pelos perfis de eletrorresistividade e pela proposta de Lachassagne et al. (2011) para perfis de alteração de rochas em zonas de falha. Observa-se que áreas de rocha pouco fraturada e por vezes aflorante ocorrem próximas a zonas com espessamento do manto de intemperismo (Figura 9). Esse contraste de espessuras do solo de alteração, rocha alterada e rocha fresca sugere a ocorrência de um meio de permeabilidade altamente heterogênea, controlada pela presença de fraturas e, consequentemente, pela direção de esforços tectônicos pretéritos e atuais.

Dessa forma, é fundamental que o histórico tectônico da região seja considerado na determinação dos grupos de fraturas com maior potencial hidráulico. A tectônica é o fenômeno gerador de descontinuidades, responsável pela abertura e reativação ou pelo fechamento de fraturas, sendo especialmente importantes os eventos neotectônicos mais recentes, que têm grande influência na atual configuração da rede de fraturas hidraulicamente ativas (FERNANDES, 2008; MORTIMER et al., 2011; MATTILA; TAMMISTO, 2012).

Os dois últimos eventos tectônicos que afetaram a área de estudo são os mais relevantes em termos de reativação de estruturas (RICCOMINI et al., 2004; SANSON, 2006; NEGRÃO, 2014). A transcorrência dextral de direção E-W, relatada como o evento recente de maior intensidade, pode estar associada à gênese ou à reativação das estruturas orientadas NW-SE, correspondentes ao Grupo 2 (Tabela 1; Figuras 3, 4 e 9, em vermelho), e ainda a estruturas NNW-SSE (Figuras 3, 4 e 9, em azul), que são as mais numerosas na área de estudo. Por fim, a distensão NW-SE pode estar associada à gênese ou à reativação das estruturas do Grupo 3 (Tabela 1), de orientação NE-
SW (Figuras 3 e 4, em verde) e ENE-WSW (Figuras 3 e 4, em rosa). Tais estruturas apresentam, portanto, um maior potencial de fluxo de água subterrânea, sendo recomendável a execução de ensaios hidráulicos para a quantificação do fluxo.

\section{CONCLUSÕES}

A correlação significativa entre os dados obtidos por diferentes técnicas, em escalas distintas, evidenciou a robustez do método proposto e seu potencial de aplicação em regiões de condições geológicas semelhantes. A metodologia proposta e os resultados gerados são uma contribuição concreta ao estudo e investigação de aquíferos fraturados no contexto nacional.

Evidenciou-se a importância de adotar abordagens baseadas em ferramentas e técnicas relativamente mais simples para fundamentar a tomada de decisão ao se eleger eventuais (se ainda necessárias) atividades invasivas mais refinadas e de maior custo, como a sequência proposta pela metodologia Discrete Fracture Network, que combina diversas técnicas para a caracterização detalhada de aquíferos fraturados. 0 método aqui proposto pode ser aplicado ainda para fins de locação de poços de monitoramento ou de produção em pontos estratégicos, com a finalidade de maximizar vazões e ou interceptar linhas de fluxo específicas.

\section{AGRADECIMENTOS}

Os autores agradecem a James $\mathrm{K}$. Henderson pelo acesso às informações das áreas de estudo; às empresas de consultoria ambiental Advisian/Worley e Jacobs pela coordenação dos trabalhos de campo e de escritório; à geóloga Dra. Amélia Fernandes, pelo apoio nos trabalhos de campo e pelas sugestões na interpretação dos dados; à geóloga Ana Luísa Porto e ao geólogo Jorge Correia Leite Arthuzzi pelo apoio nos trabalhos 
de campo; ao laboratório LATEC-CEPAS (USP) pela execução dos trabalhos de campo de geofísica; e à geóloga Mariana dos Santos Toledo Bussarello pelo apoio no tratamento de dados.

\section{REFERÊNCIAS}

AGÊNCIA NACIONAL DE ÁGUAS - ANA. Disponibilidade e demandas de recursos hídricos no Brasil. 2005. Disponível em: https://arquivos.ana.gov.br/planejamento/planos/pnrh/VF\%20DisponibilidadeDemanda.pdf . Acessado em: 15 jan. 2021.

ALBUQUERQUE, A. Análise dos padrões de fraturamento neotectônico e a sua possível aplicação na avaliação hidrogeológica da Bacia Sedimentar de Resende (RJ). In: SIMPÓSIO DE HIDROGEOLOGIA DO SUDESTE; ENCONTRO NACIONAL DE PERFURADORES DE POÇOS, 12., 2001. [Anais ...] Rio de Janeiro, p. 165-173, 2001

BARBOSA, M. B. Aplicação e desenvolvimento dos métodos de caracterização de aquíferos fraturados utilizando poços tubulares. Tese (doutorado), Instituto de Geociências, Universidade de São Paulo, São Paulo, 2019. 186 p.

BARTON, N.; CHOUBEY, V. The shear strength of rock joints in theory and practice. Rock Mechanics, v. 10, n. 1-2, p. 1-54, 1977. https://doi.org/10.1007/BF01261801

BERTOLO, R. Bases técnicas para a gestão de áreas contaminadas por solventes clorados em aquíferos fraturados. Tese (livre docência), Instituto de Geociências, Universidade de São Paulo, São Paulo, 2017. 117p.

CASTRO, F. G. Caracterização hidrogeológica e hidrogeoquímica da Bacia Sedimentar de Resende - RJ. Dissertação (Mestrado), Departamento de Geoliogia, Universidade Federal do Rio de Janeiro, Rio de Janeiro, 2000. 130p.

CHESNAUX, R.; ALLEN, D. M.; JENNI, S. Regional fracture network permeability using outcrop scale measurements. Engineering Geology, v. 108, n. 3-4, p. 259-271, 2009. https://doi.org/10.1016/i.enggeo.2009.06.024

DOMENICO, P. A.; SCHWARTZ, F. W. Physical and chemical hydrogeology. New York, Wiley, 1989.

FANTI, A.; BERTOLO, R.; VOGADO, F.; CAGNON, F.; QUEIROZ, A. P. Application of geophysical logging and straddle packers for the investigation of a fractured aquifer in a contaminated area by chlorinated solvents in Sao Paulo State, Brazil. Journal of Water Resource and Protection, v. 10, p. 1145-1168, 2017. https://doi.org/10.4236/jwarp.2017.910075

FERNANDES, A. J. Tectônica cenozóica na porção média da bacia do rio Piracicaba e sua aplicação a hidrogeologia de meios fraturados. Tese (doutorado), Instituto de Geociências, Universidade de São Paulo, São Paulo, 1997. 244p.

FERNANDES, A. J. Aquíferos fraturados: uma revisão dos condicionantes geológicos e dos métodos de investigação. Revista do Instituto Geológico, v. 29, n. 1-2, p. 49-72, 2008. https://doi.org/10.5935/0100-929X.20080005

FERNANDES, A. J.; ROULEAU, A. Simulação de deslocamentos em fraturas em basaltos da Formação Serra Geral (Ribeirão Preto, SP) e implicações para a sua transmissividade. Águas Subterrâneas, 15, suplemento, 2008.
FERNANDES, A.; RUDOLPH, D. L. The influence of Cenozoic tectonics on the groundwater-production capacity of fractured zones: a case study in Sao Paulo, Brazil. Hydrogeology Journal, v. $9, \quad$ n. $2, \quad$ p. 151-167, 2001 https://doi.org/10.1007/s100400000103

FERNANDES, A. J.; MALDANER, C.; WAHNFRIED, I.; FERREIRA, L. M. R.; PRESSINOTTI, M. M. N.; VARNIER, C.; IRITANI, M. A.; HIRATA, R. Modelo conceitual preliminar de circulação de água subterrânea do aquífero Serra Geral, Ribeirão Preto, SP. In: ABAS, CONGRESSO BRASILEIRO DE ÁGUAS SUBTERRÂNEAS, 16., 2006. [Anais...]. Curitiba, 2006.

FERNANDES, A. J.; MALDANER, C. H.; ROULEAU, A. Análise das fraturas nos basaltos de Ribeirão Preto, SP: aplicação à elaboração de modelo hidrogeológico conceitual. Geologia USP. Série Científica, v. 11, n. 3, p. 43-64, 2011. https://doi.org/10.5327/Z1519-874X2011000300003

FERNANDES, A. J.; FIUME, B.; BERTOLO, R.; HIRATA, R. C. A. Modelo geométrico de fraturas e análise da tectônica rúptil aplicados ao estudo do fluxo do aquífero cristalino, São Paulo (SP). Geologia USP. Série Científica, v. 16, n. 3, p. 71-88, 2016. https://doi.org/10.11606/issn.2316-9095.v16i3p71$\underline{88}$

FIUME, B.; FERNANDES, A. J.; BARBOSA, M.; BERTOLO, R. A.; HIRATA, R. Caracterização dos grupos de fraturas e identificação dos mais transmissivos em aquífero cristalino, em São Paulo (SP). In: CONGRESSO DE ÁGUAS SUBTERRÂNEAS, 20., 2018. [Anais....]. Campinas, Brasil, 2018.

FIUME, B.; FERNANDES, A. J.; BARBOSA, M. B.; HIRATA, R.; BERTOLO, R. A. Integrated application of geophysical loggings and fracture survey on rock exposures for identifying transmissive fractures in crystalline aquifer: case study in the city of São Paulo. Brazilian Journal of Geology, v. 50, n. 01, 2020. https://doi.org/10.1590/2317-4889202020190034

HEILBRON, M.; MOHRIAK, W. U.; VALERIANO, C. M.; MILANI, E. J., ALMEIDA, J.; TUPINAMBÁ, M. From collision to extension: the roots of the southeastern continental margin of Brazil. Atlantic rifts and continental margins, 1-32, 2000. https://doi.org/10.1029/GM115p0001

HEILBRON. M.; PEDROSA-SOARES, A. C.; CAMPOS NETO, M. C.; SILVA, L. C.; TROUW, R. A. J.; JANASI, V. A. Província Mantiqueira. In: MANTESSO-NETO, V.; BARTORELLI, A. DAL RÉ CARNEIRO, C.; BRITO NEVES, B.B. (orgs.) Geologia do continente sul-americano: evolução da Obra de Fernando Flávio Marques de Almeida. Beca, p. 203-235, 2004.

HIRATA, R.; SUHOGUSOFF, A. V.; MARCELLINI, S. S.; VILLAR, P. C.; MARCELLINI, L. A revolução silenciosa das águas subterrâneas no Brasil: uma análise da importância do recurso e os riscos pela falta de saneamento. São Paulo, Instituto Trata Brasil, 2019. 35p.

INSTITUTO BRASILEIRO DE GEOGRAFIA E ESTATÍSTICA - IBGE / Diretoria de Geociências - DGC / Coordenação de Cartografia - CCAR. Projeto Rio de Janeiro 1:25.000 (RJ-25). Disponível em: https://www.ibge.gov.br/geociencias-novoportal/modelos-digitais-de-superficie/modelos-digitais-de-superficie/10856-mde-modelo-digital-de-elevacao.html? \&t=downloads. Acesso em: 15 ago. 2017.

KELLER, G. V.; FRISCHKNECHT, F. C. Electrical methods in geo- 
physical prospecting. 1st ed. Pergamon Press, Oxford. 1966. $519 p$.

LACHASSAGNE, P.; WYNS, R.; DEWANDEL, B. The fracture permeability of hard rock aquifers is due neither to tectonics, nor to unloading, but to weathering processes. Terra Nova, v. 23, n. 3, p. 145-161, 2011. https://doi.org/10.1111/i.13653121.2011.00998.x

LOJKASEK-LIMA, P. Caracterização de detalhe do perfil vertical de contaminação em um aquífero cristalino fraturado e in temperizado - Jurubatuba - São Paulo - SP. Tese (doutorado), Instituto de Geociências, Universidade de São Paulo, São Paulo, 2018. 160p.

MABEE, S. B.; HARDCASTLE, K. C.; WISE, D. U. A method of collecting and analyzing lineaments for regional scale fractured bedrock aquifer studies. Groundwater, v. 32, n. 6, p. 884-894, 1994.

6584.1994.tb00928.x

MADRUCCI, V., TAIOLI, F., ARAÚJO, C.C.D. Análise integrada de dados de sensoriamento remoto, geologia e geofísica no estudo de aquífero fraturado, Lindóia SP. Revista Brasileira de Geofísica, v. 23, n. 4, p. 437-451, 2005. https://doi.org/10.1590/S0102-261X2005000400007

MATTILA, J.; TAMMISTO, E. Stress-controlled fluid flow in fractures at the site of a potential nuclear waste repository, Finland. Geology, v. 40, p. 299-302, 2012 https://doi.org/10.1130/G32832.1

MONTEIRO, M. D. Contribuição à caracterização hidrogeológica de maciços fraturados e solos residuais em projetos de obras subterrâneas na Região Metropolitana de São Paulo. Dissertação (Mestrado), Instituto de Geociências, Universidade de São Paulo, São Paulo, 2016. 148p.

MORTIMER, L; AYDIN, A.; SIMMONS, C. T.; LOVE, A. J. Is in situ stress important to groundwater flow in shallow fractured rock aquifers? Journal of Hydrology, v. 399, n. 3, p. 185-200, 2011. https://doi.org/10.1016/i.jhydrol.2010.12.034

NEGRÃO, A. P. Evolução tectonossedimentar e deformação rúptil cenozoica da região da bacia sedimentar de Volta Redonda (Segmento Central do Rifte Continental do Sudeste do Brasil, RJ). Tese (doutorado). Instituto de Geociências, Universidade Federal do Rio de Janeiro, Rio de Janeiro, 2014. 248p.

ODLING, N. E. Scaling and connectivity of joint systems in sandstones from western Norway. Journal of Structural Geology, v. 19, n. 10, p. 1257-1271, 1997. https://doi.org/10.1016/S0191-8141(97)00041-2

PARKER, B. L. Investigating contaminated sites on fractured rock using the DFN approach. In: NATIONAL GROUND WATER ASSOCIATION/US EPA FRACTURED ROCK CONFERENCE: STATE OF THE SCIENCE AND MEASURING SUCCESS IN REMEDIATION [Proceedings...]. 24-6, 2007.

PINO, S. Structural hydrogeology in the Kenogami uplands, Quebec, Canada. Dissertação (Mestrado), Université du Québec à Chicoutimi, Canadá, 2012.

PINO, D. S.; ROULEAU, A.; ROY, D. W. Analysis of the joint system in the Kenogami uplands bedrock aquifer: methodology and preliminary results. GeoHydro, Abstracts, 2011.
PINO, D. S.; ROY, D. W.; ROULEAU, A.; FERNANDES, A. J.; BERTOLO, R. A. Linhas de levantamento estrutural: correção do viés de orientação a partir de planilhas eletrônicas. Revista do Instituto Geológico, v. 40, n. 3, p. 49-74, 2019. https://doi.org/10.33958/revig.v40i3.675

PINO, D. S.; BERTOLO, R.; LOJKASEK-LIMA, P.; FERNANDES, A. J.; PARKER, B.; HIRATA, R. Discrete fracture network characterization using multiple, high-resolution borehole methods in a crystalline rock aquifer in tropical Sao Paulo city, Brazil. Journal of South American Earth Sciences, v. 105, 102911, 2021. https://doi.org/10.1016/i.jsames.2020.102911

PRIEST, S. D. Discontinuity analysis for rock engineering. London: Chapman \& Hall, $1993 . \quad 473 p$ https://doi.org/10.1007/978-94-011-1498-1

RATNAKUMARI, Y.; RAI, S. N.; THIAGARAJAN, S.; KUMAR, D. 2D electrical resistivity imaging for delineation of deeper aquifers in a part of the Chandrabhaga river basin, Nagpur District, Maharashtra, India. Current Science, p. 61-69, 2012.

RAYNER, S. F.; BENTLEY, L. R.; ALLEN, D. M. Constraining aquifer architecture with electrical resistivity imaging in a fractured hydrogeological setting. Journal of Environmental \& Engineering Geophysics, v. 12, n. 4, p. 323-335, 2007. https://doi.org/10.2113/JEEG12.4.323

RICCOMINI, C. Rift Continental do Sudeste do Brasil. São Paulo. Tese (doutorado), Instituto de Geociências, Universidade de São Paulo, São Paulo, 1989. 256 p.

RICCOMINI, C.; SANT'ANNA, L. G.; FERRARI, A. L. Evolução geológica do rift continental do sudeste do Brasil. In: Geologia do continente Sul-Americano: evolução da obra de Fernando Flávio Marques de Almeida, 383-405, 2004.

ROBINSON, D. A.; BINLEY, A.; CROOK, N.; DAY-LEWIS, F. D.; FERRE, T. P. A.; GRAUCH, V. J. S.; KNIGHT, R.; KNOLL, M.; LAKSHMI, V.; MILLER, R.; NYQUIST, J.; PELLERIN, L.; SINGHA, K.; SLATER, L. Advancing process-based watershed hydrological research using near-surface geophysics: a vision for, and review of, electrical and magnetic geophysical methods. Hydrological Processes, v. 22, n. 18, p. 3604-3635, 2008. https://doi.org/10.1002/hyp.6963

ROULEAU, A.; GALE, J. E. Statistical characterization of the fracture system in the Stripa granite, Sweden. International Journal of Rock Mechanics and Mining Sciences \& Geomechanics Abstracts, v. 22, n. 6, p. 353-367, 1985. https://doi.org/10.1016/0148-9062(85)90001-4

SANDER, P. Lineaments in groundwater exploration: a review of applications and limitations. Hydrogeology Journal, v. 15, n. 1, p. 71-74, 2007. https://doi.org/10.1007/s10040-006$\underline{0138-9}$

SANSON, M. S. R. Sistemas deposicionais aluviais e tectônica cenozóica na região de Volta Redonda (RJ)-Rift Continental do Sudeste do Brasil. Dissertação (Mestrado), Instituto de Geociências, Universidade Federal do Rio de Janeiro, Rio de Janeiro, 2006. 151p. https://doi.org/10.11137/2006 2 276$\underline{278}$

TELFORD, W. M.; GELDART, L. P.; SHERIFF, R. E. Resistivity methods. In: Applied geophysics. 2nd ed. Cambridge Univ. Press, Cambridge, UK, 353-358, 1990. 
https://doi.org/10.1017/CB09781139167932

TERZAGHI, R. D. Sources of error in joint surveys. Geotechnique, v. 15, n. 3, p. 287-304, 1965. https://doi.org/10.1680/geot.1965.15.3.287

TOMASI, L. C.; ROISENBERG, A. Contexto Hidrogeológico e sua Relação com a Tectônica do Sistema Aquífero Serra Geral na Bacia Hidrográfica do Rio ljuí, RS. Anuário do Instituto de Geociências, v. 42, n. 2, p. 40-49, 2019. https://doi.org/10.11137/2019_2_40_49
VAZ, L. F.; GURGUEIRA, M. D. Solos em Geologia de Engenharia. In: Geologia de Engenharia e Ambiental, ABGE, 2018. 912 p.

WAHNFRIED, I. D. Modelo conceitual de fluxo do Aquitarde Serra Geral e do Sistema Aquífero Guarani na região de Ribeirão Preto, SP. Tese (doutorado), Instituto de Geociências, Universidade de São Paulo, São Paulo, 2010. 124p. 